\title{
SODIUM NITROPRUSSIDE AND LIDOCAINE IN THE ANAESTHETIC MANAGEMENT OF PHEOCHROMOCYTOMA
}

\author{
Moustafa El-Naggar, ${ }^{*}$ Eleuerto Suerte, $\nmid$ and E. Rosenthal
}

The surgical Management of pheochromocytoma, once associated with 50 per cent mortality, ${ }_{1}^{1}$ is now approached with a prospect of less than 5 per cent mortality. ${ }^{2}$ This dramatic change in outcome has been vastly aided by understanding of the physiological and biochemical events encountered in this syndrome and by the use of pharmacological agents with specific agonistic or antagonistic properties at the recently identified adrenergic receptor sites.

During the last year we were involved in the surgical management of two cases of pheochromocytoma. The pre-operative evaluation and preparation of these patients were similar to that reported by other investigators. ${ }^{2-3}$ However, we modified the management during operation by using diazepam, fentanyl, nitrous oxide and oxygen, and pancuronium to induce and maintain anaesthesia, and sodium nitroprusside to control the episodic haemodynamic pressor responses whenever phentolamine failed to do so at a reasonable dose. In addition, lidocaine was used prophylactically to avert the occurrence of serious dysrhythmia subsequent to tracheal intubation or excessive manipulation.

\section{CAse Report \#1}

A 40-year-old male patient, under treatment for hypertension, was admitted to the hospital because of symptoms and signs of left ventricular failure.

The patient was treated with digitalis, diuretics, and diazoxide. Close monitoring of the blood pressure showed marked fluctuations ranging from $240 / 150$ to $160 / 90$ torr. Pheochromocytoma was suspected and this diagnosis was confirmed (Table I).

When the diagnosis of pheochromocytoma was established, administration of phenoxybenzamine (Dibenzyline) was started with an initial dose of $20 \mathrm{mg}$ TID which was subsequently increased to $50 \mathrm{mg}$ QID. Propranolol $40 \mathrm{mg}$ p.o. QID was also added to the medication when the patient complained of anginal pains.

Preanaesthesia medication consisted of diazepam $10 \mathrm{mg}$, morphine sulphate 5.0 $\mathrm{mg}$, and scopolamine $0.5 \mathrm{mg}$ given intramuscularly one hour before operation. Prior to induction of anaesthesia the necessary monitoring systems (Table II) and two intravenous infusions were established, the required medication was prepared, and lidocaine $60 \mathrm{mg}$ was given intravenously. Anaesthesia was induced with diazepam $25 \mathrm{mg}$ and fetanyl $0.25 \mathrm{mg}$ followed by pancuronium $8.0 \mathrm{mg}$. Another $60 \mathrm{mg}$ of lidocaine was then administered. A $9.5 \mathrm{~mm}$ cuffed tracheal tube was

From the Departments of Anaesthesiology, Rush Presbyterian St. Luke's Medical Center and Cook County Hospital, $\uparrow$ and the Department of Paediatrics, Abraham Lincoln Medical School, $f$ University of Illinois, Chicago, Illinois, U.S.A. 
TABLE I

Levels of the Different Catecholamines in Urine Collected in 24 hours Pre- and POST-OPERATIVEly AND In THE TUMOR

\begin{tabular}{|c|c|c|c|c|c|}
\hline & \multirow[b]{2}{*}{ Normal } & \multicolumn{2}{|c|}{ Case \#1 } & \multicolumn{2}{|c|}{ Case $\# 2$} \\
\hline & & Pre-op. & Post-op. & Pre-op. & Post-op. \\
\hline VMA & $7.0 \mathrm{mg} \%$ & 19.4 & 4.4 & 30.8 & 2.26 \\
\hline $\begin{array}{l}\text { Metanephrine plus } \\
\text { normetanephrine } \\
\text { Homovanillic acid } \\
\text { Norepinephrine } \\
\text { Epinephrine }\end{array}$ & $\begin{array}{c}2.0 \mu \mathrm{g} \% \\
10.0 \mu \mathrm{g} \% \\
0.07 \mu \mathrm{g} \% \\
0.03 \mu \mathrm{g} \%\end{array}$ & $\begin{array}{l}9.8 \\
2.4 \\
0.6 \\
0.21\end{array}$ & $\begin{array}{l}1.4 \\
4.1 \\
0.06 \\
0.06\end{array}$ & $\begin{array}{l}12.0 \\
1.85 \\
0.82 \\
0.11\end{array}$ & $\begin{array}{l}0.73 \\
0.66 \\
0.02 \\
0.02\end{array}$ \\
\hline Location of the tumor & & \multicolumn{2}{|c|}{$\begin{array}{l}\text { Left adrenal gland } \\
\text { and superior pole of } \\
\text { the left kidney }\end{array}$} & \multicolumn{2}{|c|}{ Organ of Zuckerkandle } \\
\hline $\begin{array}{l}\text { Weight of the tumor } \\
\text { Norepinephrine in the tumor }\end{array}$ & & \multirow{2}{*}{\multicolumn{2}{|c|}{$\begin{array}{l}23 \mathrm{~g} \\
1499.5 \\
\mathrm{mg} / \mathrm{g} \\
537 \mathrm{mg} / \mathrm{g}\end{array}$}} & \multicolumn{2}{|c|}{$\begin{array}{l}26.8 \mathrm{~g} \\
578 \mathrm{mg} / \mathrm{g}\end{array}$} \\
\hline Epinephrine in the tumor & & & & & $g / g$ \\
\hline
\end{tabular}

placed with ease and anaesthesia was maintained with 70 per cent nitrous oxide with oxygen and supplemental doses of fentanyl and pancuronium. Ventilation was controlled with a mechanical ventilator adjusted to maintain arterial blood gases and $\mathrm{pH}$ within normal range. During exploration of the abdomen, the blood pressure increased to $200 / 140$ torr. Phentolamine $5.0 \mathrm{mg}$ was given in divided doses which reduced the blood pressure to $120 / 70$ torr.

In the next hour there was intermittent modest increase in the blood pressure which was controlled by fractional doses of phentolamine with a total of $10 \mathrm{mg}$.

TABLE II

Monitoring Systems and Specific Medications in Anaesthetic Management of Neural Crest Lesion

A. Before Induction of Anaesthesia:

1. ECG

2. Percutaneous catheterization of the radial artery for direct measurement of the arterial blood pressure

3. Sphygmomanometery

4. Chest stethoscope

B. After Induction of Anaesthesia and Tracheal Intubation:

1. Rectal Temperature

2. CVP

3. Urine output

4. Oesophageal stethoscope

5 . Intermittently: blood gases, $\mathrm{pH}, \mathrm{Hct}$, and arterial mixed venous oxygen content difference

6. Estimated blood loss

C. Medication Prepared Before Induction of Anaesthesia:
1. Lidocaine
2. Phentolamine
3. Sodium nitroprusside $(100 \mathrm{mg} / 500 \mathrm{ml})$
4. Sodium Bicarbonate
5. Epinephrine $(1 \mathrm{mg} / 250 \mathrm{ml})$
6 . Norepinephrine $(2 \mathrm{mg} / 250 \mathrm{ml})$
7. Propranolol
8. Human albumin solution 10 per cent
9. Blood typed and cross-matched 
Thereafter, during manipulation of the tumor the blood pressure rose to $230 / 170$ and did not respond to phentolamine $(10 \mathrm{mg})$. The surgical procedure was stopped temporarily and sodium nitroprusside infusion was started at the rate of $100 \mu \mathrm{g} /$ minute; $100 \mathrm{mg}$ of lidocaine was also administered concomitantly. This resulted in a reduction of blood pressure to $120 / 80$ torr, while the pulse rate remained stable at $80-90 /$ minute with no disturbances of rhythm. The operation was resumed and the tumor was completely resected three hours after the start of anaesthesia. The blood pressure stabilized at 120/70 to 140/90 torr. The total dose of sodium nitroprusside given was $15 \mathrm{mg}$ and that of lidocaine $520 \mathrm{mg}$.

The procedure consisted of left adrenalectomy and incidental splenectomy (because of ruptured splenocolic ligament) and lasted 5 hours and 15 minutes. The patient was transferred to post-anaesthesia recovery where close monitoring continued and 40 per cent humidified oxygen was administered. The patient was extubated on the first post-operative day and discharged to the ward.

Post-operatively, the blood pressure ranged from 160 to 180 torr systolic and 100 to 120 torr diastolic. On the 4th post-operative day urinary catecholamines and catecholamine derivatives were within normal limits (Table I).

\section{Case Report \#2}

A 55-year-old female patient was admitted to the hospital because of weight loss, general malaise, spells of profuse perspiration, pounding headaches, flushing and episodic palpitations. The patient was treated previously for hypertension and diabetes, and had a subtotal thyroidectomy for diffuse toxic goiter.

On admission vital signs were as follows: Blood pressure $220 / 100$ torr, pulse $92 /$ minute, respiration $16 /$ minute, and temperature $37.5^{\circ} \mathrm{C}$. She was $165 \mathrm{~cm}$ tall and weighed $58 \mathrm{~kg}$.

The patient was managed with methyl-dopa $500 \mathrm{mg}$ TID, and diuretics. Because changes in the blood pressure were noted to be episodic, pheochromocytoma was suspected and the diagnosis was established (Table I). Phenoxybenzamine was started with an initial dose of $10 \mathrm{mg}$ QID, increased to $50 \mathrm{mg}$ BID. After ten days of treatment, vital signs were as follows: blood pressure 120/80 torr, pulse rate $100 /$ minute, respiratory rate $16 /$ minute, temperature $36.8^{\circ} \mathrm{C}$. ECG showed normal sinus rhythm. Angiogram revealed a tumor corresponding to the first lumbar sympathetic ganglion. Surgical removal of the tumor was planned.

Premedication consisted of morphine $5 \mathrm{mg}$, diazepam $5 \mathrm{mg}$, and scopolamine $0.4 \mathrm{mg}$ administered intravenously one hour before operation. Prior to induction of anaesthesia lidocaine $60 \mathrm{mg}$ was given intravenously. Anaesthesia was then induced with diazepam $20 \mathrm{mg}$ intravenously and fentanyl $0.2 \mathrm{mg}$ followed by pancuronium $6 \mathrm{mg}$. Before laryngoscopy another bolus of lidocaine $60 \mathrm{mg}$ was given. Orotracheal intubation was accomplished using an $8 \mathrm{~mm}$ (ID) cuffed tracheal tube and respiration was controlled mechanically. Anaesthesia was sustained with nitrous oxide, oxygen, fentanyl and pancuronium.

During the first hour, the blood pressure ranged between 120/80 to 140/90 torr without the need for hypotensive agents. Subsequently, coinciding with manipula- 
tion of the tumor, the blood pressure rose to $220 / 100$ torr and the pulse was $150 /$ minute; this was controlled with phentolamine $\mathrm{HCl} 2 \mathrm{mg}$.

During the next three hours of surgery, there were several hypertensive episodes; the blood pressure rose up to 294/150 torr. Fractional doses of phentolamine, totalling $42 \mathrm{mg}$ were given to control the blood pressure. Subsequently, this was less effective and sodium nitroprusside $50-100 \mu \mathrm{g} /$ minute and intermittent doses of lidocaine ( $50-100 \mathrm{mg}$ ) were then used to control the blood pressure and cardiac rhythm as described in the previous case report. The total dose of sodium nitroprusside administered was $10 \mathrm{mg}$ and of lidocaine $370 \mathrm{mg}$.

When the tumor was completely resected, the blood pressure dropped to $90 / 60$, a five per cent albumin infusion was administered rapidly; this raised the blood pressure to $120 / 60$ and stabilized the pulse rate at $80 /$ minute.

At the end of the operation the patient was taken to post-anaesthesia recovery room where close monitoring of the blood pressure and pulse rate continued. On the first post-operative day the patient was extubated and on the third day she was discharged to the ward. Post-operative levels of catecholamines and its derivates are shown in Table $I$.

\section{Discussion}

The pre-operative preparation of patients with pheochromocytoma should include an alpha adrenergic blocking agent. Phenoxybenzamine is the drug of choice because it induces stable persistent blockade of the alpha receptors, which allows improvement in the cardiovascular status, expansion of the blood volume, decrease in the basal metabolic rate and plasma free fatty acids ${ }^{0, i}$ and protection against the pre-operative episodes of hypertension and cardiac dysrhythmias. ${ }^{8}$

Some investigators ${ }^{4,9}$ prefer to use chlorpromazine to achieve alpha adrenergic receptor blockade. However, DeBlasi ${ }^{10}$ reported that chlorpromazine aggravates the hypotension after removal of the neural crest lesion, and in vivo studies showed that alpha adrenergic receptor blockade with chlorpromazine is unpredictable. ${ }^{11}$ Also, chlorpromazine under appropriate conditions enhances the pressor response to epinephrine.

Although considerable attention has been directed to the use of beta blocking drugs such as propranolol for the pre-operative preparation of patients with pheochromocytoma ${ }^{13}$, the unequivocal need for beta blockade has been only rarely noted. ${ }^{2,3}$ Therefore, propranolol is only indicated when the sympathoadrenal influence on cardiac performance is excessive enough to cause serious dysrhythmia, angina or myocardial ischaemia, ${ }^{4}$ as in our first case. Under such conditions, propranolol should be administered only after adequate alpha adrenergic receptor blockade by phenoxybenzamine. ${ }^{14}$

The alpha and beta adrenergic blocking agents should be withheld 12 hours before operation to regain some responsiveness in the cardiovascular system to catecholamine release, to enable the surgeon to identify the tumor and ensure its total resection, and to avert hypotension during operation due to sudden withdrawal of catecholamines.

For pre-anaesthesia medication of pheochromocytoma patients, we prefer the use of diazepam, morphine and scopolamine, given intramuscularly one hour 
before anaesthesia. Diazepam offers the desired sedation, tranquility, amnesia and antiemesis, increases CNS threshold of convulsions to lidocaine, ${ }^{15}$ and has no hyperalgesic effect on somatic pain sensation. ${ }^{10}$

Morphine enhances the sense of well being, raises the threshold to pain, prevents the release of norepinephrine from post-sympathetic ganglionic fibers, ${ }^{17}$ and lowers its level in man. ${ }^{18}$ The histamine releasing effect of morphine was exaggerated in human beings ${ }^{19}$ and the drug was well tolerated by our patients. Scopolamine has antiemetic and amnesic properties and protects the patient from the effect of excessive vagal stimulation without marked tachycardia.

In spite of adequate preparation and premedication, the intra-operative management of neural crest lesions still presents three major problems: (1) episodic hypertension that occurs spontaneously or during induction of anaesthesia, tracheal intubation, or surgical manipulation, (2) serious disturbances of rhythm and (3) severe hypotension that may follow induction of anaesthesia, administration of adrenergic blocking agents, excessive haemorrhage, or when the venous drainage of the tumor is secured.

Anticipating these problems, the anaesthesiologist should use efficient monitoring systems; have ready appropriate therapeutic measures (Table II); select the anaesthetic technique that ensures smooth induction, free airway, adequate gas exchange, intense analgesia, muscular relaxation, and which protects the patient from excessive somatic, autonomic or psychogenic reflexes.

Although continuous spinal anaesthesia has been used successfully in such cases, ${ }^{20}$ most investigators ${ }^{2-5}$ prefer tracheal intubation, controlled ventilation and the use of nondepolarizing neuromuscular blocking agents. To facilitate the induction and maintenance of anaesthesia, almost every known sequence of anaesthetic agents and medication have been used by some investigators and criticized by others. We prefer the sequence of diazepam, fentanyl, pancuronium, and nitrous oxide with oxygen because of the negligible effects of the individual agents on the cardiovascular system. This sequence may be criticized; a primary reason is the finding ${ }^{21}$ that Innovar-nitrous oxide anaesthesia may be accompanied by excessive release of epinephrine. However, this increase in catecholamine release may be related to droperidol because Jaatella ${ }^{18}$ found that fentanyl did not change its level in plasma.

It may be argued that the use of potent inhalational general anaesthetics is desirable in pheochromocytoma because in high concentration they tend to inhibit the reflex and neurogenically mediated release of catecholamines. ${ }^{22}$ However, it is a common observation that the use of potent general anaesthetics in pheochromocytoma did not prevent the episodic haemodynamic pressor responses, while aggravating episodes of hypotension. In the balanced anaesthesia sequence these episodes can be averted and managed by more specific agents.

An integral part of our anaesthetic management of pheochromocytoma is the use of lidocaine 50 to $100 \mathrm{mg}$ prophylactically before induction of anaesthesia, tracheal intubation, surgical manipulation or sudden rise in the blood pressure, to avoid ventricular dysrhythmias. This regimen has been effective in preventing disturbances of ventricular rhythm in our pheochromocytoma cases, even in the presence of pre-operative dysrhythmia and very active tumor tissue, as in the first 
case reported here. The half-life of epinephrine and norepinephrine in the blood is extremely short and their release during the surgical management of pheochromocytoma is episodic in nature. ${ }^{22}$ Therefore, to block the alpha adrenergic receptors, phentolamine in small incremental doses $(1-2 \mathrm{mg}$ ) is the agent of choice because of its rapid onset and short duration of action. Tachyphylaxis, however, is the major disadvantage of phentolamine. Continued administration of the drug to control the blood pressure results in unmanageable hypotension after resection of the tumor. At this juncture, we advise the use of sodium nitroprusside to control the blood pressure because of its efficacy, rapid onset and short duration of action. This drug has also been used successfully in the medical management of pheochromocytoma hypertensive crisis resistent to phentolamine. ${ }^{23}$ Sodium nitroprusside, however, has to be freshly prepared and since cyanide toxicity has been observed when the drug was given in excessive doses, ${ }^{24,25}$ it should be used judiciously.

Propranolol has been reported to be effective in controlling the blood pressure when phentolamine tachyphylaxis developed in one case of pheochromocytoma. ${ }^{26}$ However, it is our opinion and the opinion of others ${ }^{22,2,4}$ that the administration of propranolol should be discouraged in these cases. The cardiac depressant properties of propranolol coupled with peripheral vasoconstriction and fairly long duration of action has resulted in complete heart block and post-operative death. ${ }^{4}$ In the experimental animal, propranolol was shown to have a deleterious effect on cardiac performance in the presence of hypovolaemia. ${ }^{27}$

It was our observation and reported by other recent investigators ${ }^{2-4}$ that hypotension was not marked after the venous drainage of these neural crest lesions was controlled and there was no need for vasopressor agents. This can be related to the proper pre-operative preparation of the patient.

\section{SUMMARY}

Recent advances in pharmacology, physiology, and biochemistry have revealed the pathophysiologic derangements encountered in pheochromocytoma, and the rational foundations for its management; this is illustrated in reports of two cases.

For pre-operative preparation we use phenoxybenzamine to block the alpha adrenergic receptors, as it allows improvement in the cardiovascular status, expansion of the blood volume, decrease in the basal metabolic rate and plasma free fatty acids and protection against adrenergic crisis. We use propranolol pre-operatively subsequent to effective alpha adrenergic receptor blockade only to control serious dysrhythmia, angina or myocardial ischaemia. The alpha and beta blocking agents are withheld 12 hours prior to operation.

Preanaesthesic medication includes morphine, diazepam and scopolamine and induction and subsequent maintenance of anaesthesia are achieved with diazepam, fentanyl, pancuronium, nitrous oxide and oxygen. Lidocaine (50-100 mg) is administered prophylactically before induction of anaesthesia, tracheal intubation and concomitant with exaggerated pressor responses to surgical manipulations. These latter reactions are managed by phentolamine $(1-5 \mathrm{mg})$ until the first mani- 
festation of tachyphylaxis; at this juncture we resort to a drip of sodium nitroprusside (50-100 $\mu \mathrm{g} /$ minute).

Successful management of pheochromocytoma demands anticipation of potential problems, prior preparation of necessary medication, adequate monitoring and close post-operative observation.

\section{RÉSUMÉ}

Les acquisitions récentes dans le domaine de la pharmacologie, de la physiologie et de la biochimie ont permis une meilleure compréhension de la physiopathologie $\mathrm{du}$ phéochromocytome, et une conduite thérapeutique plus rationnelle. Nous présentons nos cas à titre d'illustration.

Nous utilisons la phenoxybenzamine en préparation à l'intervention. Le blocage $\alpha$ ainsi produit améliore l'état cardiovasculaire, permet la réexpansion du volume sanguin, amène une diminution du métabolisme basal et des acides gras plasmatiques libres, en plus de protéger contre la crise adrénergique. En pré-opératoire, le propranolol n'est utilisé qu'après obtention d'un blocage $\alpha$ efficace, pour le contrôle d'arythmies graves, d'angine ou d'ischémie myocardique. Les bloqueurs $\alpha$ et $\beta$ sont cessés 12 heures avant la chirurgie.

Nos opérés ont reçu du diazepam, de la morphine et de la scopolamine en prémédication. Pour l'induction et le maintien de l'anesthésie, nous avons utilisé le diazepam, le fentanyl, le pancuronium, le protoxyde d'azote et l'oxygène. La lidocaine en doses de 50 à $100 \mathrm{mg}$ a été administrée de façon préventive avant l'intubation trachéale, et aussi lors des poussées hypertensives secondaires aux manipulations. Ces poussées hypertensives ont été contrôlées à l'aide de Régitine (1-5 mg) jusqu'à ce que survienne la tachyphylaxie, alors que nous avons passé au nitroprussiate $(50-100 \mu \mathrm{g} / \mathrm{min})$.

L'approche d'un phéochromocytome nécessite l'anticipation des problèmes potentiels, la préparation à l'avance des médicaments qui peuvent devenir nécessaires subitement, un monitoring adéquat et une surveillance attentive en post-opératoire.

\section{REFERENCES}

1. APGar, V. \& PAPPER, E.M. Pheochromocytoma: anesthetic management during surgical treatment. Arch. Surg. 62: 634-648 (1951).

2. Perry, L.B. \& Gould, A.B., Jr. The anesthetic management of pheochromocytoma: effect of pre-operative adrenergic blocking drugs. Anesth. \& Analg. 51: 36-40 (1972).

3. Gitlow, S.E., Pentsemlidis, D., \& Bertani, L.M. Management of patients with pheochromocytoma. Amer. Heart Journal 82: 557-567 (1971).

4. Bingham, W., Elliott, J., \& Lyons, S.M. Management of anesthesia for pheochromocytoma. Anaesthesia 27:49-60 (1972).

5. Crout, J.R. \& Brown, B.R., JR. Anesthetic management of pheochromocytoma: the value of pheoxybenzamine and methoxyflurane. Anesthesiology 30:29-36 (1969).

6. Englemen, K., Mueller, P.S., \& SJoendsia, A. Elevated plasma free fatty acid concentrations in patients with pheochromocytoma. Changes with therapy and correlations with basal metabolic rate. New Engl. J. Med. 270: 865-870 (1964).

7. Enclemen, K. \& Sjoerdsma, A. Chronic medical therapy for pheochromocytoma: a report of four cases. Ann. Intern. Med. 61: 229-241 (1964).

8. Ross, R.J., Prichard, B.N.C., Kaufman, L., Robertson, A.I., \& Harries, B.J. Pre-opera- 
tive and operative management of patients with pheochromocytoma. Brit. Med. J. 1: 191-198 (1967).

9. Huxe, D.N. Pheochromocytoma in the adult and in the child. Amer. J. Surg. 99: 458-496 (1970)

10. DeBlasi, S. The management of the patient with a pheochromocytoma. Brit. J. Anaesth. 38: 740-752 (1966)

11. Nickelsson, M. \& Collien, B. Drugs inhibiting adrenergic nerves and structures innervated by them, chapter 26. The pharmacological basis of therapeutics. L.S. Coodman and A. Gillman. The Macmillan Co., N.Y., N.Y., 533-564 (1975).

12. Jarvik, M.E. Drugs used in the treatment of psychiatric disorders, chapter 12. The pharmacological basis of therapeutics. L.S. Goodman and A. Gillman. The Micmillan Co., N.Y., N.Y., 151-203 (1970)

13. Buist, N.R., Mijer, F., \& O'Brien, D. Treatment of a pheochromocytoma with a B adrenergic blocking agent. Arch. Dis. Child. 435-436 (1966).

14. Crago, R.N., Eckholdt, J.W., \& Wiswell, J.G. Pheochromocytoma. Treatment with A and $B$ adrenergic blocking drugs. J.A.M.A. 202: 870-874 (1967).

15. Dejong, R.H., Heavner, J.D., \& DeOliviera, L.E. Effects of nitrous oxide on the lidocaine seizures threshold and diazepam protection. Anesthesiology 37: 299-303 (1972).

16. DundeE, J.W. \& Clark, R.S.J. Non-barbiturate intravenous anaesthetics, chapter 34. Ceneral anesthesia, third edition, volume 1. Editors: T. Cecil Gray and J.F. Nunn. Publisher, Appleton-Century-Crafts, N.Y., N.Y., 513-529.

17. Colnie, A.B., Kosterlitz, H.W., \& Taylor, D.W. Effect of morphine on some sympathetically innervated effectors. Brit. J. Pharmacol. 17:539 (1961)

18. JaAtella, A., NikKI, P., \& TAKki, S.T. Effect of dextromoramide, fentanyl and morphine on the plasma catecholamine levels. Ann Clinic. Res. 3: 107-111 (1971).

19. JAFFe, J.H. Narcotic analgesics, chapter 15. The pharmacological basis of therapeutics. L.S. Goodman and A. Gillman. The Macmillan Co., N.Y., N.Y. 237-275 (1970).

20. VAxdair, L. Pheochromocytoma. Lecture \#212B. Annual Refresher Course lectures. A.S.A. 1-3 (1971).

21. Giesecke, A.H., JR., Jenkins, M.T., Crout, J.R., \& Collett, J.M. Urinary epinephrine and norepinephrine during Innovar nitrous oxide anesthesia in man. Anesthesiology 28: 701704 (1967)

22. Pender, J.W., Fox, M., \& Basso, L.V. Diseases of the endocrine system. Chapter 3, Anesthesia and uncommon diseases. Edited by J. Kadis and L.B. Kadis, W.B. Saunders, Publisher. Philadelphia, 104-144 (1973).

23. Nourok, D.S., Gwivup, G., \& HAxwr, G.J. Phentolamine resistant pheochromocytoma treated with sodium nitroprusside. J.A.M.A. 183: 841-844 (1963).

24. JACK, R.D. Toxicity of sodium nitroprusside correspondence. Brit. J. Anaesth. 46: 952 (1974).

25. MCRaE, W.R. \& Owen, M. Severe metabolic acidosis following hypotension induced with sodium nitroprusside. Brit. J. Anaesth. 46: 795-797 (1974).

26. Salear, M.R. \& Ivanokovic, A.D. Management of phentolamine resistant pheochromocytoma with beta-adrenergic blockade: a case report. Brit. J. Anaesth. 4l: 1087-1090 (1969).

27. WeIs, K.H. \& BRACHEBUSH, H.D. On the cardiovascular effect of propranolol during halothane anesthesia in normovolemic and hypovolemic dogs. Brit. J. Anaesth. 42: 272$279(1970)$. 